\title{
Morphological Studies of the Altered Pulps of the New Zealand White Rabbit after Resection of the Inferior Alveolar Nerve and/or the Superior Cervical Ganglion'
}

\author{
J. K. AVERY, D. S. STRACHAN, R. E. CORPRON AND C. F. COX \\ Oral Histology Laboratory, Department of Oral Biology, \\ University of Michigan School of Dentistry, \\ Ann Arbor, Michigan 48104
}

\begin{abstract}
This study was carried out to determine the effects of denervation of the pulp organs of teeth, particularly on the odontoblasts and their processes. Therefore, resection of the inferior alveolar, cervical sympathetic, or a combination of both types of nerves supplying the mandibular incisor teeth of New Zealand white rabbits was performed and the results compared to adjacent, unaltered teeth. Neural stains were used to evaluate the presence or absence of nerve elements, while histochemical and titrametric methods were employed to determine the presence, location and concentration of cholinesterase enzymes in these teeth. Dilation of blood vessels was noted after cervical sympathetic resection and larger nerve trunks as well as peripherally located fine fibers were absent in the pulps following inferior alveolar nerve resection. Further, irregular dentin formation and associated small openings in the tips of the teeth were observed after nerve resection. Titrametric analysis indicated a significant decrease in the concentration of cholinesterase in the pulp organ of incisors 15-19 days after resection of either the inferior alveolar nerve or both inferior alveolar and cervical sympathetic nerves. Only a slight decrease in the concentration of cholinesterase was noted after removal of the cervical sympathetic nerve alone. Histochemical results confirmed a decrease in cholinesterase after resection of the inferior alveolar, cervical sympathetic or both nerves. The concentration of the oxidative enzyme, succinic dehydrogenase, however, increased after all three types of nerve resection. This increase was apparent particularly in the odontoblastic cells underlying the predentin.
\end{abstract}

A number of investigators have reported the effects of denervation on the growth patterns of teeth. King ('37) sectioned the cervical sympathetic nerves in rabbits and noted a temporary acceleration of the growth of incisors. He attributed this acceleration to an increase in blood supply which occurred after sectioning. Taylor and Butcher ('51) found a 20-30\% increase in the rate of eruption of rat incisors following inferior alveolar nerve resection. They concluded that the loss of sensation which resulted caused a fracture of the continuously erupting teeth. The lack of occlusion may have contributed to the increased rate of eruption. Edwards and Kitchen ('37) noted that resection of sym- pathetic nerves caused a $\mathbf{2 - 1 5 \%}$ accelerated tooth growth in kittens, while resection of the inferior alveolar nerve produced no definite effect. Bishop and Dorman ('63) reported that stimulation of the superior cervical ganglion caused vasoconstriction of the mandibular artery. Severing of the mandibular nerve resulted in an increased blood flow in this artery.

Most of these authors have discussed the changes in numbers and distribution of nerves in the pulps of denervated teeth. Butcher and Tayor ('51) noted a decreased

Received Aug. 7, '69. Accepted May 24, '71.

1. This research was supported by U.S.P.H.S. Research grant DE-01604 from the National Institute of
Dental Research, National Institutes of Health, Bethesda, Md. 
number of nerves, although in other respects, the pulps appeared normal. They concluded that the maintenance of tooth structure did not depend on innervation. Christensen ('40) found that nearly all nerve fibers in the pulp disappeared after sectioning of the fifth nerve, but removal of the superior cervical ganglion caused no appreciable change in nerve distribution. Fearnhead ('61) sectioned the inferior alveolar nerve in the monkey and reported that after one month, there remained only a few isolated nerves in the pulps of teeth. Weatherred ('65) stimulated the peripherally cut end of the inferior alveolar nerve. An increase in intrapulpal pressure was recorded using a sensitive pressure transducer placed in contact with the pulp. Stimulation of the cervical sympathetic ganglia, on the other hand, produced a decrease in pulp pressure. A sample of saline from a prepared cavity in contact with the pulp was found to contain a very small amount of smooth muscle stimulating hormone. Following stimulation of the inferior alveolar nerve, an increased amount of this hormone was found in the saline of the cavity preparation. Muscle tissue response to this smooth muscle stimulating hormone resembled that obtained with synthetic bradykinin. An active enzymatic substance capable of destroying this smooth muscle stimulating hormone was found by Kroeger and Krivoy ('64) in the pulps of rat incisors.

The purpose of the present investigation was to study the changes in pulps and dentin of continuously growing incisor teeth of the rabbit following resection of the inferior alveolar, cervical sympathetic or both nerves. Ikeda ('36) has described the histology of the rabbit pulp in detail and this reference will be used throughout this paper. In addition to a histologic evaluation of neural elements, the distribution of cholinesterase and succinic dehydrogenase using histochemical techniques was studied. Quantitative determinations of cholinesterase levels by titrametric analysis were also carried out.

\section{METHODS AND MATERIALS}

New Zealand rabbits were selected for this study to facilitate sugical techniques and because they have continuously devel- oping incisor teeth which adequately record the effects of resection. In this manner, the effects of denervation could be studied in the formative areas as well as in older zones of the pulp. Animals weighing between 2.0 and $4.0 \mathrm{~kg}$ were divided into three groups of nine each and three controls, and initially sedated with $1.5 \mathrm{~cm}^{3}$ of a solution containing $1: 1$ sodium pentobarbitol $50 \mathrm{mg} / \mathrm{cm}^{3}$ and $0.9 \%$ sterile sodium chloride. This solution was administered in the marginal vein of the ear.

The inferior alveolar nerve (I.A.N.), cervical sympathetic nerve (S.C.G.), or a combination of both (I.A.N.-S.C.G.) nerves were resected. Following resection, an interval of 15-19 days was allowed for nerve degeneration. Operations were performed only on the right side with the left side serving as a control. Terramycin was postoperatively added to the drinking water to prevent infection.

The I.A.N. was approached from the medial aspect of the inferior border of the mandible (fig. 1). The periosteal attachment of the medial pterygoid muscle to the mandible was separated in approaching the mandibular foramen. The latter is located just medial to and approximately $1.5 \mathrm{~cm}$ above the point at which the facial artery crosses the inferior aspect of the mandible. Surgical silk was tied around the nerve approximately $5 \mathrm{~mm}$ from the foramen and the nerve was sectioned distal to this point. Visual observation of the remaining distal stump was then made, and the proximal end was sutured to the medial pterygoid muscle to prevent I.A.N. reapposition. At the time of sacrifice, a second dissection of the area was done to determine whether the I.A.N. had remained severed.

For S.C.G. resection, the omohyoid and sternohyoid muscles were exposed and separated to reveal the carotid sheath lying adjacent to the trachea (fig. 2). Longitudinal dissection of the carotid sheath exposed the sympathetic trunk or cord which was then followed cephalad to the ganglion. In all cases, the right S.C.G. with its cranial branches was removed along with a portion of the ascending sympathetic trunk. Success of the operation was noted by comparing the decrease in pupil size of the right to the left eye. A period of 15-19 


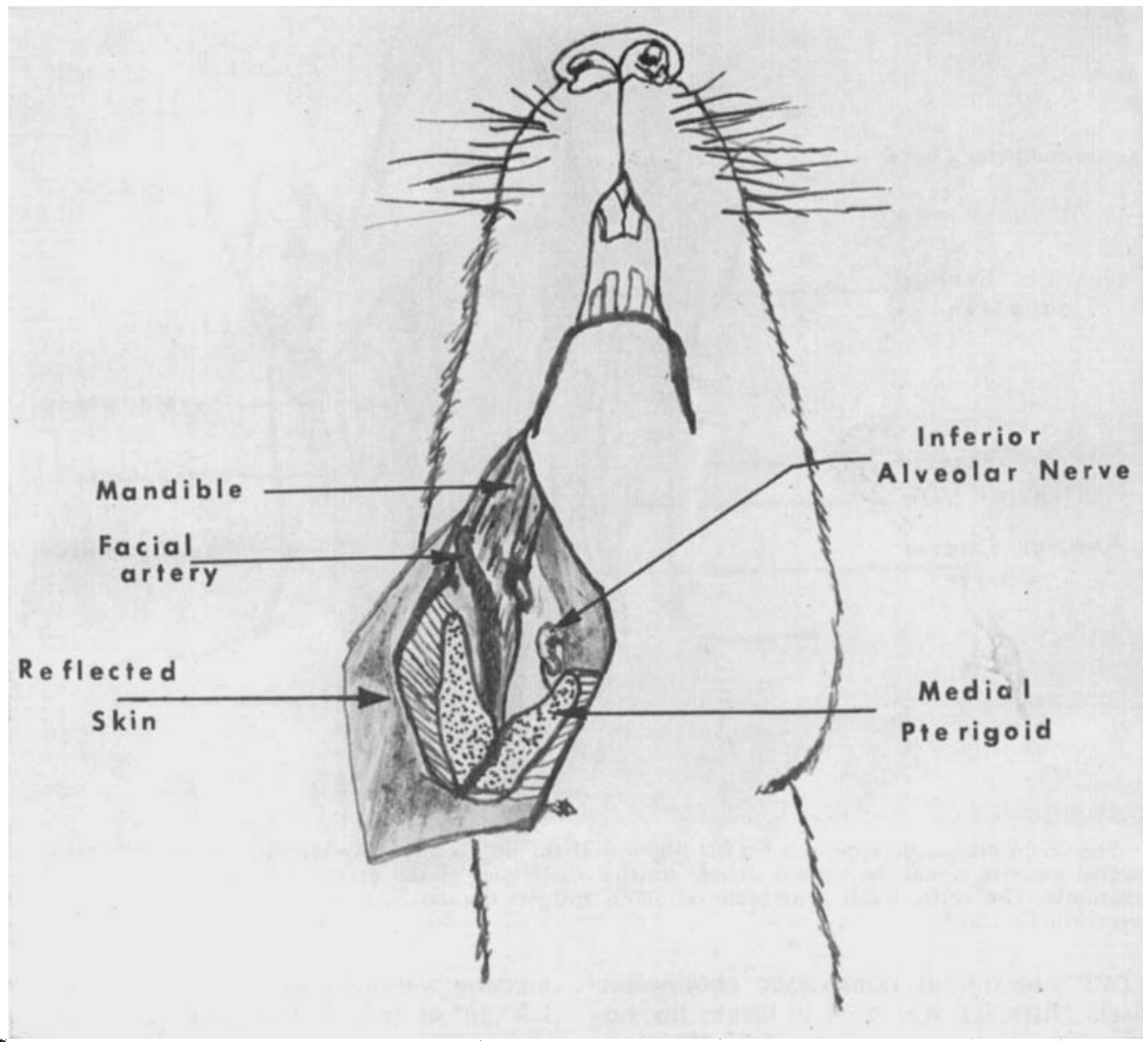

Fig. 1 A schematic approach to locate, tie and section the I.A.N. The periosteal attachment of the medial pterygoid muscle was removed from the angle of the mandible. The nerve was dissected proximally for a few $\mathrm{mm}$. A silk suture was tied around the nerve which was then resected distal to the suture. The proximal stump of the nerve was sutured into the medial pterygoid muscle to prevent reapposition of the I.A.N,

days was allotted for nerve degeneration at which time the animals were sacrificed and the mandibles removed.

Tissues were prepared for histologic observation by fixation in $10 \%$ neutral buffered formalin at $4^{\circ} \mathrm{C}$. Jaws were decalcified in formic acid buffered with sodium citrate, embedded in Paraplast, and serially sectioned at 10-16 $\mu$. Staining procedures carried out included hematoxylin and eosin, Masson's connective tissue stain, and the Lison method for mucopolysaccharides using alcian blue with chlorantine red fast 5B. Rowle's silver stain was used for con- trolled impregnation of nerve fibers using Sym-Collidine buffer to maintain a $\mathrm{pH}$ of 7.3 .

Histochemical procedures were carried out on both normal and resected nerve pulps. Pulp tissues were removed and frozen in $\mathrm{CO}_{2}$ immediately after the animal was sacrificed. Sections were cut on a cryostat and mounted serially. Both the techniques of Koelle ('62) and KarnovskyRoots ('64) were used in the localization of cholinesterases. The latter direct coloring technique was employed with a $10^{-6} \mathrm{M}$ solution of di-isopropyl fluorophosphate 


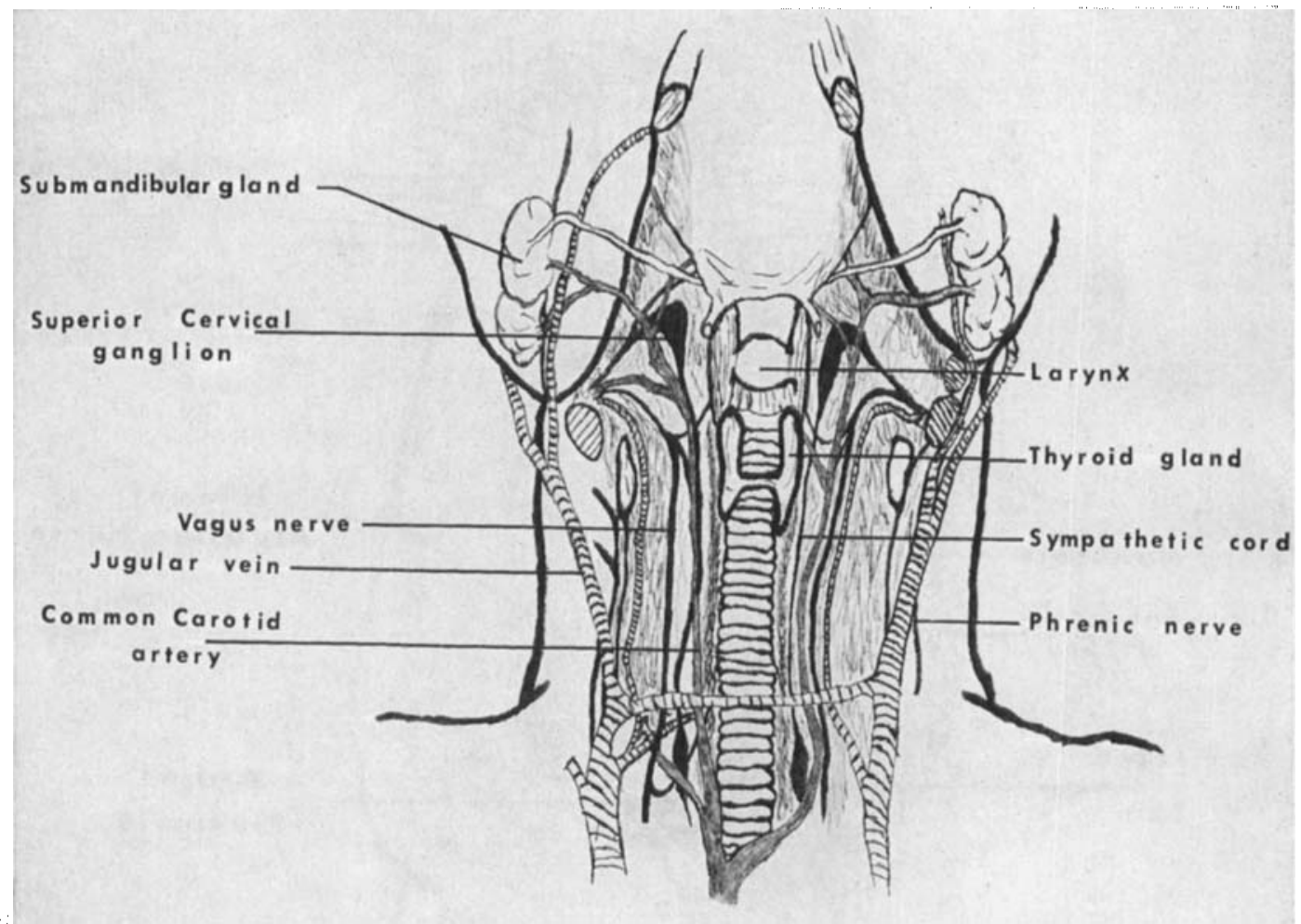

Fig. 2 A schematic approach for the removal of the S.C.G. The strap muscles (not shown) were dissected away to reveal the carotid sheath. Further dissection of the sympathetic trunk was completed cranially. The entire S.C.G. was removed along with its cranial branches and several microns of the sympathetic trunk.

(DFP) to inhibit nonspecific cholinesterases. Nitro BT was used to locate the respiratory enzyme succinic dehydrogenase which would appear as a blue diformazan precipitate at the sites of activity.

Titrametric methods, as described by Augustinsson ('57), were used to analyze the cholinesterase (AChE) activity. Entire pulps were incubated in an acetylcholine substrate which resulted in a release of choline and acetic acid. The latter was titrated with $\mathrm{NaOH}$. The rate of addition of base sufficient to maintain a constant $\mathrm{pH}$ of 8.0 indicates the degree of hydrolysis of the substrate acetylcholine and activity of the AChE enzyme. The animals were killed, and the tooth pulps were removed, weighed, homogenized at $4{ }^{\circ} \mathrm{C}$, and finally mixed with $1 \mathrm{~cm}^{3}$ of distilled water for each $50 \mathrm{mg}$ of pulp. Titrations were carried out on a $\mathrm{pH}$ meter calibrated in $0.01 \mathrm{pH}$ units. The reaction mixture was made up of equal volumes of $1.5 \mathrm{~cm}^{3}$ of pulp homogenate and $1.5 \mathrm{~cm}^{3}$ of $6 \times 10^{-3} \mathrm{M}$ acetylcholine chloride. This solution was placed in a $5 \mathrm{~cm}^{3}$ beaker and continuously mixed with a magnetic stirring rod. The $\mathrm{pH}$ of the mixture was usually brought to 8.0 in less than four minutes. Readings of the micrometer dial on the microsyringe were then recorded at intervals of one minute, and expressed as millicicromoles of $\mathrm{NaOH}$ added over time to maintain a $\mathrm{pH}$ of 8.0.

For each type of resection, rates of reaction were calibrated individually and then evaluated for the total control and experimental groups. In each case, the unoperated side which served as a control was titrated under the same conditions as the operated side. A fresh solution of acetylchloride (Merck) $3 \times 10^{-3} \mathrm{M}$ was prepared for each animal to maintain a constant substrate solution. The $\mathrm{pH}$ meter was re- 
calibrated after each sample to within 0.01 of a pH unit using a $\mathrm{pH} 7.0$ buffer solution. The temperature was kept constant at $25^{\circ} \mathrm{C}$.

\section{RESULTS}

\section{Histologic}

Fifteen to nineteen days after resection of the I.A.N. of the rabbit incisor, all main nerve bundles and most fine fibers were missing with the exception of those located along the blood vessels of the pulp. Rowle's silver stain revealed the presence of a few degenerating segments of nerves in sharp contrast to the appearance of the adjacent control pulp. Neither the normal nor the I.A.N. resected pulp showed evidence of an organized peripheral parietal layer of nerve bundles. Myelinated nerves appeared evenly distributed throughout the normal pulps with the larger bundles in a more central location. No large trunks were observed in the normal pulps. These pulps contained only a few fibers per bundles located parallel to the long axis of the tooth. The fine nerve fibers visible along the blood vessels in the normal pulps appeared similar to those observed following I.A.N. resection. Thus the outstanding characteristic of the tooth pulps after I.A.N. resections was the loss of large myelinated nerve trunks (figs. $3,4,7,8$ ).

S.C.G. resection had a dramatic effect on the pulp. All of the blood vessels appeared dilated. Dilation of the pulp vessels appeared to crowd the connective tissue elements of the pulp to some degree. Dilated capillaries were apparent even among odontoblasts with some compression of the latter. Neural stains failed to reveal any nerves in the walls of the blood vessels, although larger neural trunks were observed through the pulp (fig, 9). These neural trunks were not, however, associated with blood vessels. In other respects, the connective tissue of S.C.G. resected pulps appeared normal (figs. 5, 9).

Removal of both the I.A.N. and S.C.G. caused the most noticeable effect on the pulp. In some instances, dilation of blood vessels was sufficient to produce compression among some odontoblasts (fig. 6). Silver staining revealed no evidence of neural elements either in the walls of ves- sels or elsewhere in the pulp organ (figs. $6,10)$.

One of the more interesting effects of these resection studies can be seen in figures 11-14. Among teeth on which an I.A.N. resection had been performed, there was a small opening in the dentin at the incisor tip (fig. 12). Lack of dentin formation resulted in a small tubular defect which was filled with necrotic cells. This tubule could be seen to extend from the pulp all the way to the incisal edge of the tooth. In S.C.G. resections, altered dentin formation was quite apparent (fig. 13). Large tubular defects which contained blood vessels and living cells were visible. Near the tip of the incisor, the cells appeared to be necrotic (fig. 12). In the combination I.A.N.-S.C.G. resections, this condition was even more exaggerated. The dentin appeared gnarled or irregular in formation and contained a defect which opened onto the oral cavity (fig. 14). Small vessels and living cells were found in this defect except near the surface where a plug of dead cells existed.

\section{Histochemical}

Resection of the I.A.N. resulted in a reduction of specific cholinesterase in the dental pulps (fig. 20). This was probably due to the absence of the inferior alveolar nerve supply to these pulps. The amount of di-isopropyl flurophosphate resistant $\mathrm{ChE}$ in the blood vessels appeared similar to that in the nonresected pulps (figs. 19-22). A definite reduction of $\mathrm{ChE}$ in the region of the odontoblasts was observed in these pulps as compared to those in controls. On the other hand, there appeared to be heavier staining of succinic dehydrogenase following I.A.N. resection when compared to control pulps (figs. 15-18). Removal of the S.C.G. resulted in an increased cholinesterase reaction throughout the pulp. There was a conspicuous absence of cholinesterase staining along the vessels (fig. 21). Similar to I.A.N. resection, S.C.G. resection resulted in a decrease in cholinesterase in the region of the odontoblasts. An increase in succinic dehydrogenase was noted following S.C.G. resection as compared to its control (fig. 17).

When both I.A.N. and S.C.G. were removed, the dilated vessels again gave the 

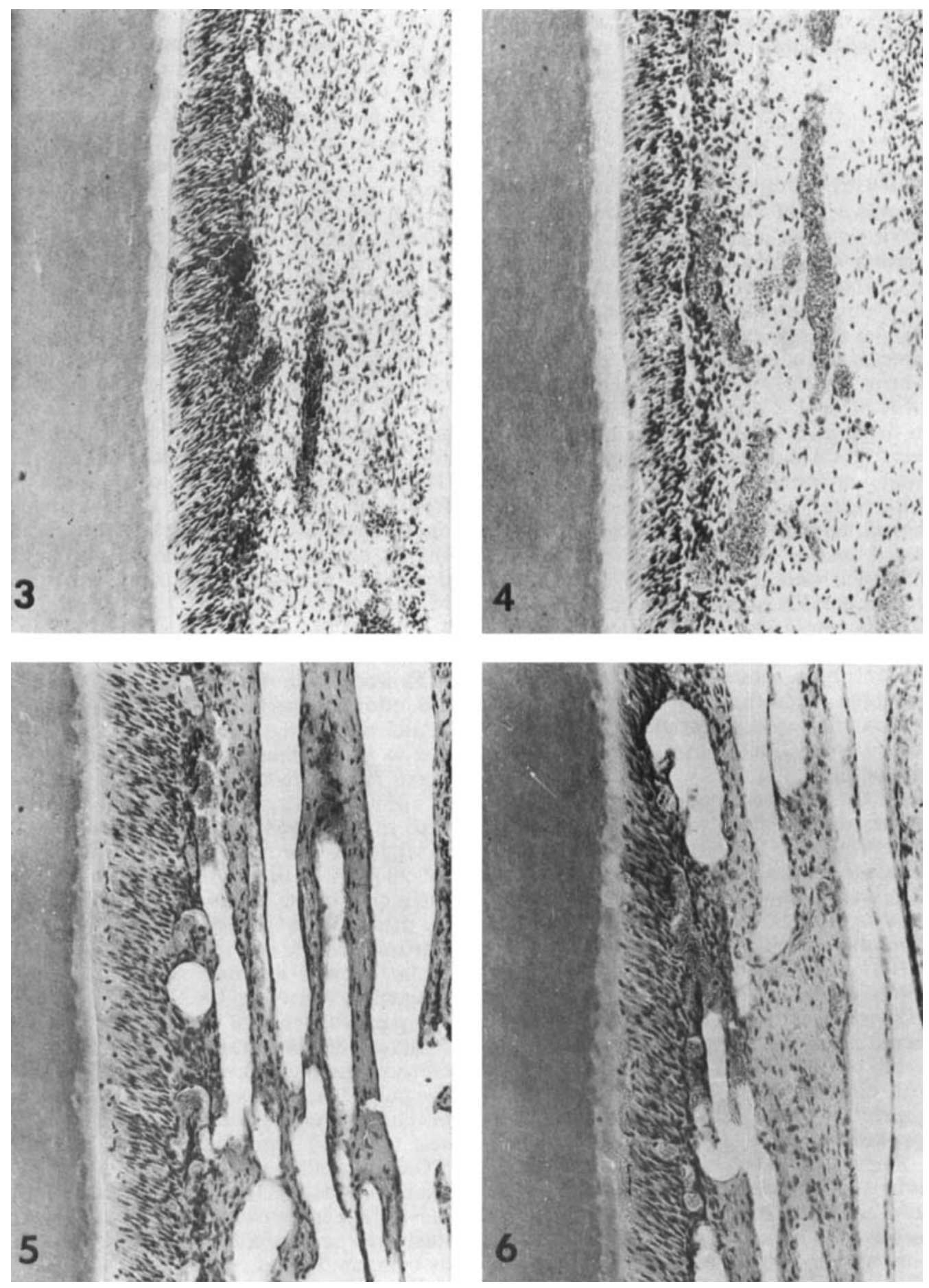

Figures 3-6 
pulp the appearance of increased cholinesterase reaction; however, there was an absence of staining along the nerve fibers (fig. 22). The succinic dehydrogenase reaction was much more intense than in its control (fig. 18).

\section{Titrametric}

I.A.N. resection resulted in lower individual rates of reaction on the experimental as compared to the control side. Figure 23 represents the rate of reaction for the control side as $3.1 \times 10^{-5} \mathrm{M}$ or $11.60 \mathrm{~m} \mu$ moles of base used during the titration procedure. The rate of reaction for the experimental side was $2.1 \times 10^{-5} \mathrm{M}$ or $6.10 \mathrm{~m}_{\mu}$ moles of base. Thus, a reduction of $5.5 \mathrm{~m}_{\mu}$ moles of base was noted for the operated side. A comparison of the entire I.A.N. group to its control counterpart revealed a combined reaction rate of $3.6 \times$ $10^{-5} \mathrm{M}$ for the experimental group and $4.9 \times 10^{-5} \mathrm{M}$ for the controls. There was thus a significant decrease in AChE activity after I.A.N. resection.

Following S.C.G. resections, higher individually observed rates of reaction were recorded for control than for experimental pulps. Figure 24 represents one observation of the effects of S.C.G. resection. The rate of reaction of this particular control sample pulp was $4.1 \times 10^{-5} \mathrm{M}$ of $11.80 \mathrm{~m}_{\mu}$ moles of base added. Its operated S.C.G.

Fig. 3 A longitudinal section through the middle third of a normal rabbit incisor. The blood vessels, normally dispersed among fibroblasts of the pulp, are distributed evenly. The odontoblast zone is shown on the left. A cell rich or cell free zone is not evident. Masson trichrome, $\times 25$.

Fig. 4 A longitudinal section of an I.A.N. resected rabbit incisor (19 days). The vessels are normally distributed without any observable dilation. The odontoblasts are not disarranged nor do the pulpal fibroblasts appear altered. Masson trichrome, $\times 60$.

Fig. 5 A longitudinal section through the middle third of an S.C.G. resected rabbit incisor pulp (19 days). Dilation of the larger vessels as well as those smaller vessels paralleling odontoblasts is noted. Little change of pulpal cell dispersal or of gross morphology of the odontoblasts is seen. Masson trichrome, $\times 50$.

Fig. 6 A longitudinal section through the middle third of an I.A.N.-S.C.G. resected rabbit incisor pulp (19 days). Dilation of the vessels is observed which causes displacement of cells in the pulp. There is no change in odontoblast morphology nor is there pulpal cellular dispersal. Masson trichrome, $\times 50$. counterpart exhibited a reaction rate of $3.7 \times 10^{-5} \mathrm{M}$ or $10.60 \mathrm{~m}_{\mu}$ moles of base. The difference of $1.20 \mathrm{~m}_{\mu}$ moles was attributed to S.C.G. resection. Grouping the S.C.G. samples, a combined reaction rate of $3.9 \times 10^{-5} \mathrm{M}$ was recorded as compared to a combined rate of $4.4 \times 10^{-5} \mathrm{M}$ for the controls. This difference was not significant.

The series of combined I.A.N.-S.C.G. resection also evidenced a decrease in $\mathrm{AChE}$ activity. Figure 25 shows a comparison of reaction rates for a control and experimental pulp. The rate of reaction of the control pulp was $4.4 \times 10^{-5} \mathrm{M}$ or $14.24 \mathrm{~m} \mu$ moles of base, while its operated counterpart had a rate of $3.4 \times 10^{-5} \mathrm{M}$ or $9.30 \mathrm{~m} \mu$ moles of titrated base. The difference of $4.20 \mathrm{~m}_{\mu}$ moles of base represented the change of acetylcholine hydrolysis as a result of combined I.A.N.-S.C.G. resection. A comparison of average rates of reaction for this series revealed a rate of $4.6 \times$ $10^{-5} \mathrm{M}$ for the control group and $3.8 \times$ $10^{-5} \mathrm{M}$ for the experimental pulps.

In each group the mean differences between experimental and control were compared using the student $\mathrm{T}$ test. Assuming values smaller than 0.05 are significant, only in the case of the inferior alveolar nerve resection was a significant difference found between experimental and control. The significant levels were smaller than 0.03 for the I.A.N., 0.40 for the S.C.G. and 0.25 for the combination resections (fig. 26).

\section{DISCUSSION}

The continuously erupting incisor of the rabbit was found to be a good experimental tool for study of the effects of loss of the I.A.N. and/or S.C.G. nerve supply. At the growing or apical end of the root, active cell proliferation was noted, while near the tip of the tooth, cells were undergoing degenerative changes. The results of this study indicate that the physiologic function of the odontoblast varies with its location in the pulp. These cells near the root apex presented a much more positive reaction for succinic dehydrogenase than near the tip of the crown. It is possible that dentinogenesis is more active at the root apex.

The effects of resection of either I.A.N. or S.C.G. were apparent after 15-19 days. 

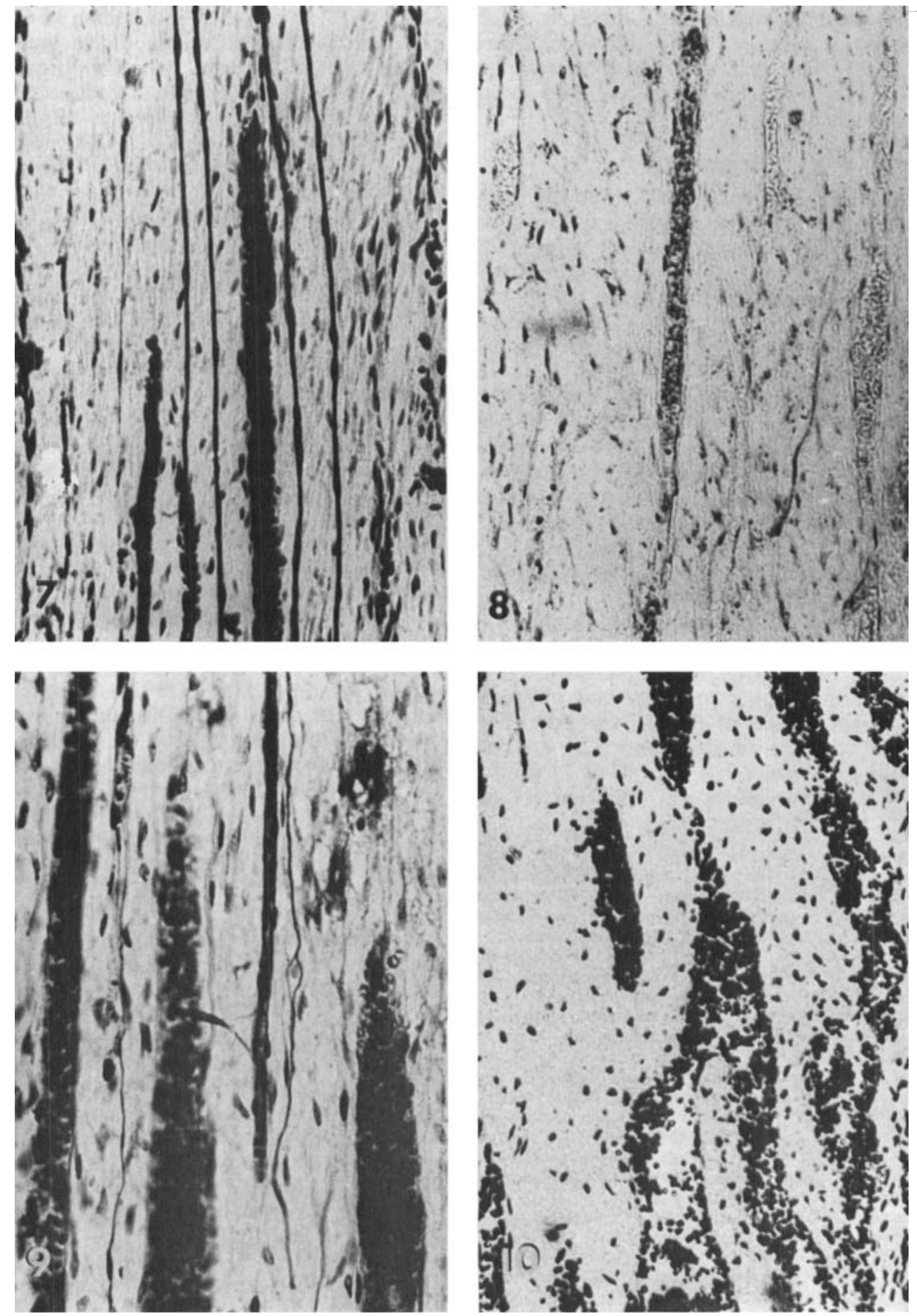

Figures 7-10 
The absence of neural elements, both the large diameter, myelinated fibers and the fine myelinated and unmyelinated fibers, was demonstrated adequately with Rowle's silver stain. The effects of S.C.G. resection were most dramatic because of the dilitation of blood vessels throughout the pulp. It was thought that S.C.G. resection would cause a significant increase in pulpal cholinesterase (ChE), but this was not the case. The absence of neural elements around the vessels and the reduction of $\mathrm{ChE}$ in the pulpal cells in the resected teeth apparently counteracted any increase in this enzyme due to the increase in blood volume. The significant drop in $\mathrm{ChE}$ after I.A.N. resection suggests that the acetylcholine is functioning in the pulpal neural system. This was apparent from histochemical techniques, with the titrametric technique providing a clear picture of the quantitative difference.

Perhaps the most interesting observation was that of the alteration of dentin formation after I.A.N. resection. This finding was reported in the growing incisor of rats by Weatherred, Kroeger and Smith ('63a,b). It is of interest that the irregular and defective dentin was found in the oldest area of the tooth tip. Only slight alteration of the incremental pattern of dentin forma-

Fig. 7 A longitudinal section through a control rabbit incisor. Myelinated nerve trunks are seen within the pulp as well as finer unmyelinated nerves adjacent to and on vessels. Rowle's silver stain, $\times 70$.

Fig. 8 A longitudinal section through an I.A.N. resected rabbit incisor (19 days). There is loss of all large nerve trunks as compared to the control; however, finer nerves remain on the vessels. Rowle's silver stain, $\times 70$.

Fig. 9 A longitudinal section through an S. C. G. resected rabbit incisor pulp (19 days). A dramatic reduction of fine nerves occurs along the vessels which appear dilated. Several myelinated nerves throughout the pulp as well as a large nerve trunk may be observed. Rowle's silver stain, $\times 70$.

Fig, 10 A longitudinal section through an I.A.N. resected rabbit incisor ( 19 days). There is complete loss of all large myelinated nerve trunks as well as smaller unmyelinated nerves that are normally associated with the vessels. Dilation of vessels may be noted. Rowle's silver stain, $\times 70$. tion was seen at the growing end of the tooth. It is again interesting that the altered dentin was accentuated where it was subject to attrition. The effects of wear on the tips of the incisor teeth seemed to be related to opening of pits from the pulp to the surface of the tooth. These alterations in the neural resected tooth suggest that the inferior alveolar nerve plays a role in the formation of dentin.

\section{LITERATURE CITED}

Augustinsson, K. B. 1957 Assay methods for cholinesterases. Methods of Biochemical Analysis, Vol. V: Chap. 1.

Bishop, I. G., and H. L. Dorman 1963 Changes in perfusion pressure in the mandibular artery induced by functional alterations of the superior cervical ganglion. J. Dent. Res., 42: $777-782$.

Butcher, E. O., and A. C. Taylor 1951 The effects of denervation and ischemia upon the teeth of the monkey. J. Dent. Res., 30: 265-275.

Christensen, K. 1940 Sympathetic nerve fibers in the alveolar nerves and nerves of the dental pulp. J. Dent. Res., 19: 227-242.

Edwards, L. F., and P. C. Kitchen 1938 Does resection of nerves supplying mandible affect development of teeth? J. Dent. Res., 17: 115124.

Fearnhead, R. W. 1961 The neurohistology of human dentine. Proc. Roy Soc. of Med., 54: 877-884.

Ikeda, M. 1936 A new method of staining the dental pulp. Jour. of Amer. Dent. Assoc., 23: 2147-2159.

Karnovsky, M. J., and L. Roots 1964 A "direct coloring" thiocholine method for cholinesterases. J. Histochem. and Cytochem., 12: 219-221.

King, J. D. 1937 Dietary deficiency, nerve le. sions and the dental tissue. J. Physiol., 88: 6277.

Koelle, G. B. II 1962 Cytological localization of AChE. J. of Pharmacy and Pharmacology, 14: 65-90.

Kroeger, D. C., and W. Krivoy 1964 Texas Rept. Biol. Med., 22: 205-209.

Taylor, A. C., and E. O. Butcher 1951 The regulation of eruption rate in the incisor teeth of the white rat. J. Exp. Zool., 117: 165-188.

Weatherred, J. G. 1965 Peripheral nervous system effects in the dental pulp of the rat and dog. Thesis.

Weatherred, J. G., D. C. Kroeger and E. L. Smith 1963a Federation Proc., 22: 287.

- 1963b International Association Dental Research 41st Meeting, Abstract 16. 

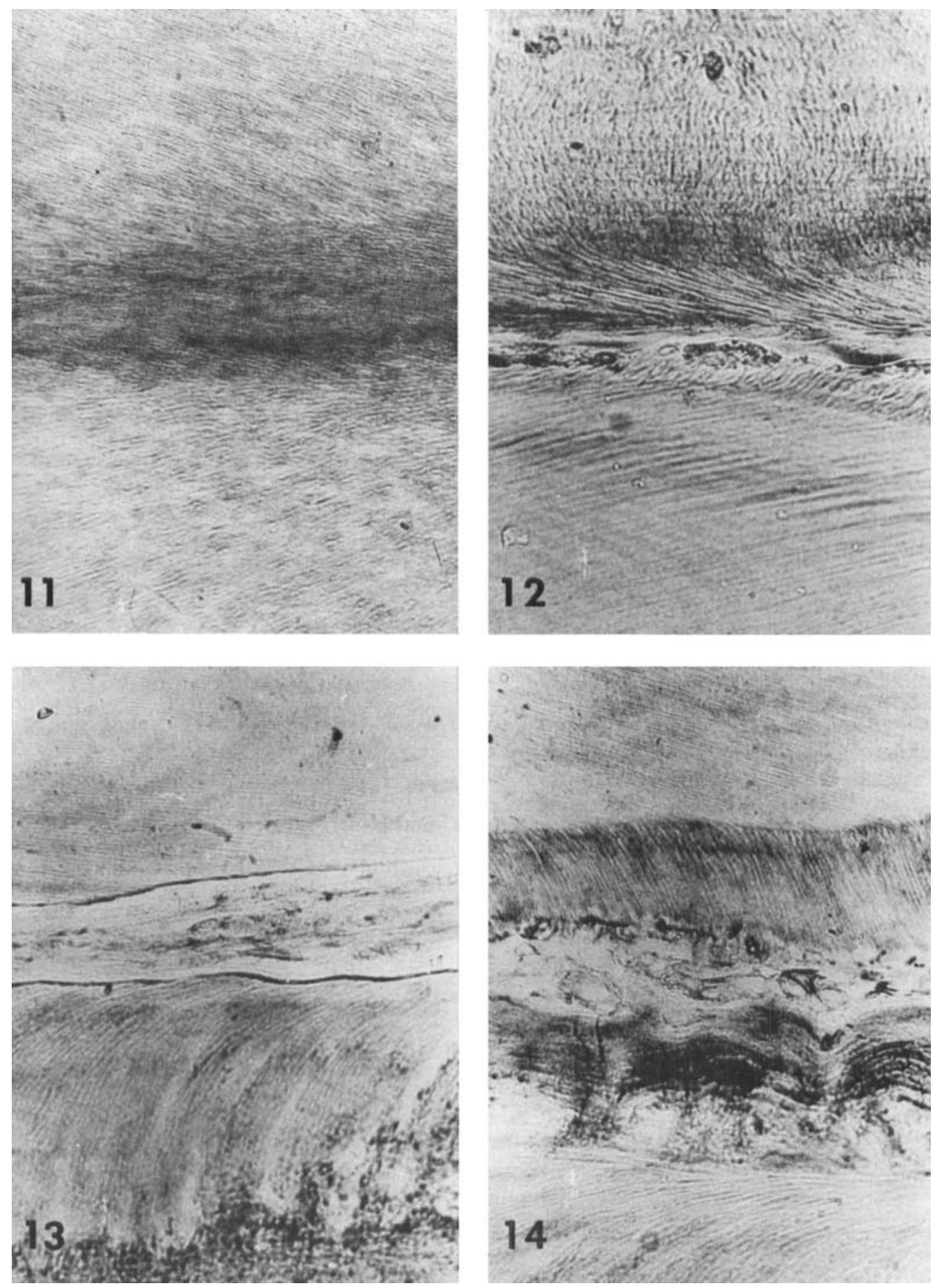

Fig. 11 A longitudinal section towards the tip of a control rabbit incisor. There is even layering of dentin with closure of the pulpal canal at the tip. Rowle's silver stain, $\times 20$.

Fig. 13 A longitudinal section near the tip of an S.C.G. resected rabbit incisor (19 days). There is little change in the new dentin. Rowle's silver stain, $\times 20$.

Fig. 12 A longitudinal section near the tip of an I.A.N. resected rabbit incisor (19 days). The pulpal canal was not completely closed. Some small vessels may be seen in the centrally located canal. There is also some distortion of the new dentin. Rowle's silver stain, $\times 20$.

Fig. 14 A longitudinal section through an I.A.N.-S.C.G, resected rabbit incisor (19 days). The new dentin is gnarled and distorted. The incisal canal remains open. Sloughed off pulp cells fill the canal at the tip. Rowle's silver stain, $\times 20$. 

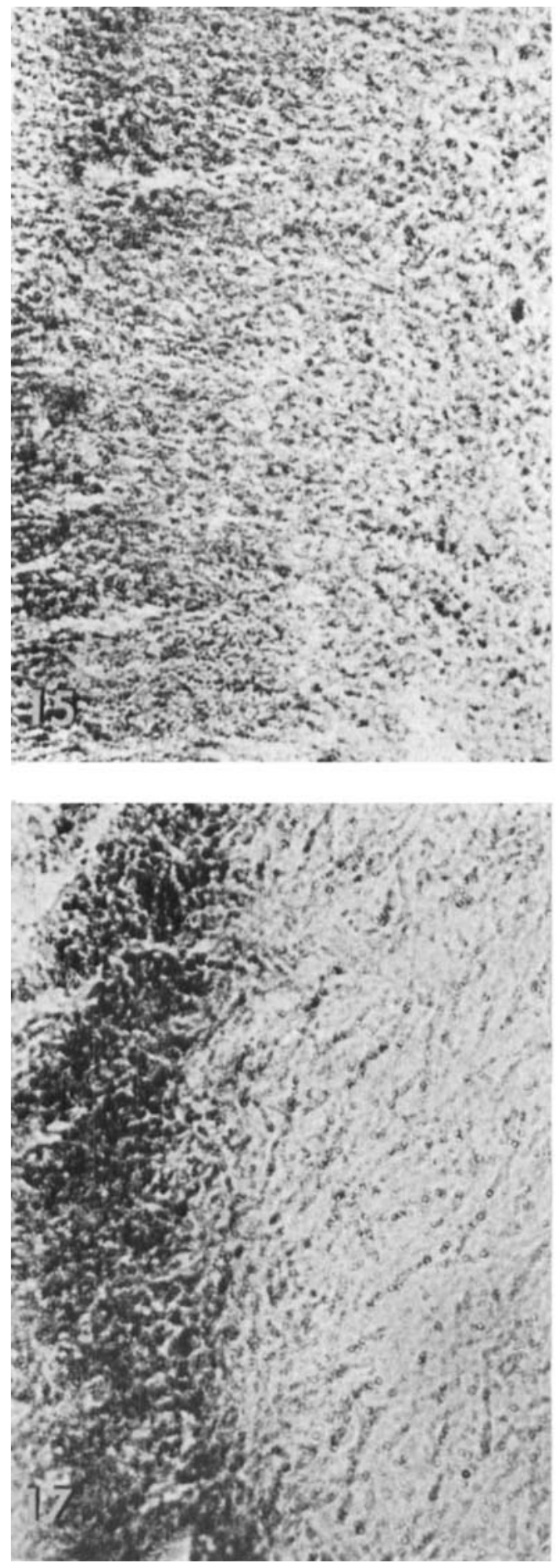

Fig. 15 A section through the middle third of a control rabbit incisor. Succinic dehydrogenase activity is seen as a dark diaformazan deposit along the odontoblasts. There is scattered activity throughout the pulp. Stain for succinic dehydroge. nase activity. $\times 140$.

Fig, 17 A section through the middle third of an S.C.G. resected rabbit incisor with a relatively intense reaction along the odontoblasts. Stain for succinic dehydrogenase activity, $\times 160$.
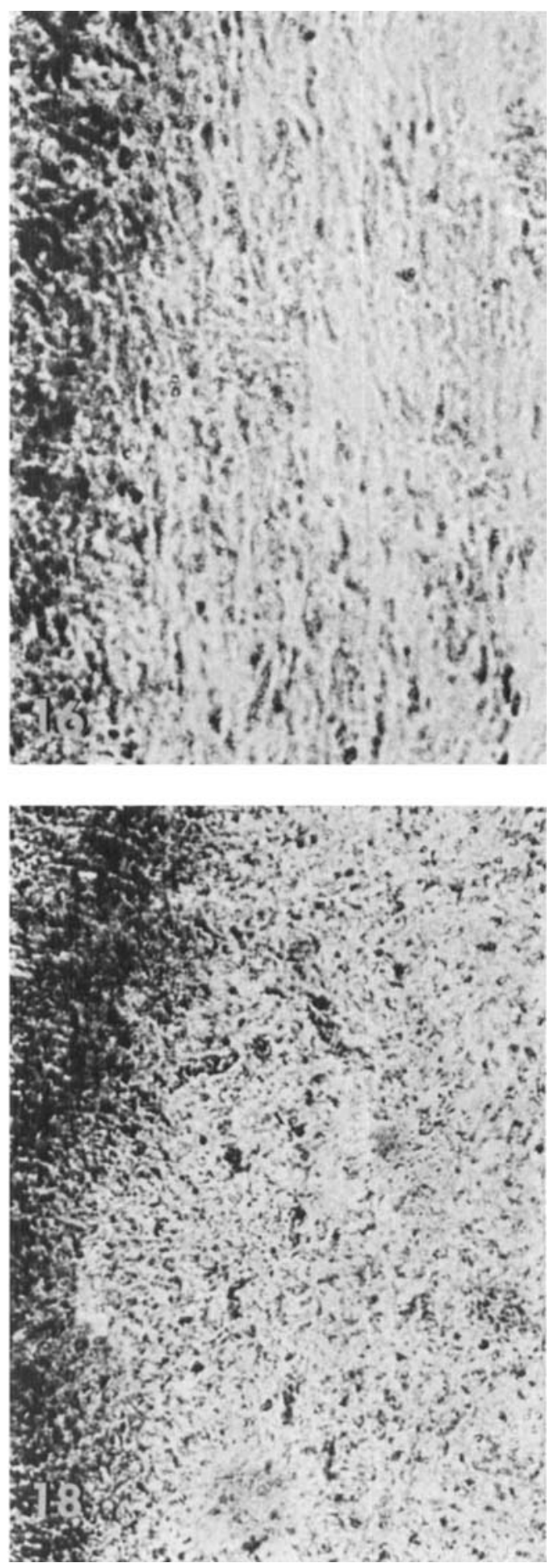

Fig. 16 A section through the middle third of an I.A.N. resected rabbit incisor ( 19 days). There appears to be an increase in reaction along the odontoblast zone. Stain for succinic dehy. drogenase activity, $\times 160$.

Fig. 18 A section through the middle third of an I.A.N.-S.C.G. resected rabbit incisor. There is a dramatic increase in the diaformazan deposit on the odontoblast zone as well as in the pulp. Stain for succinic dehydrogenase activity, $\times 160$. 

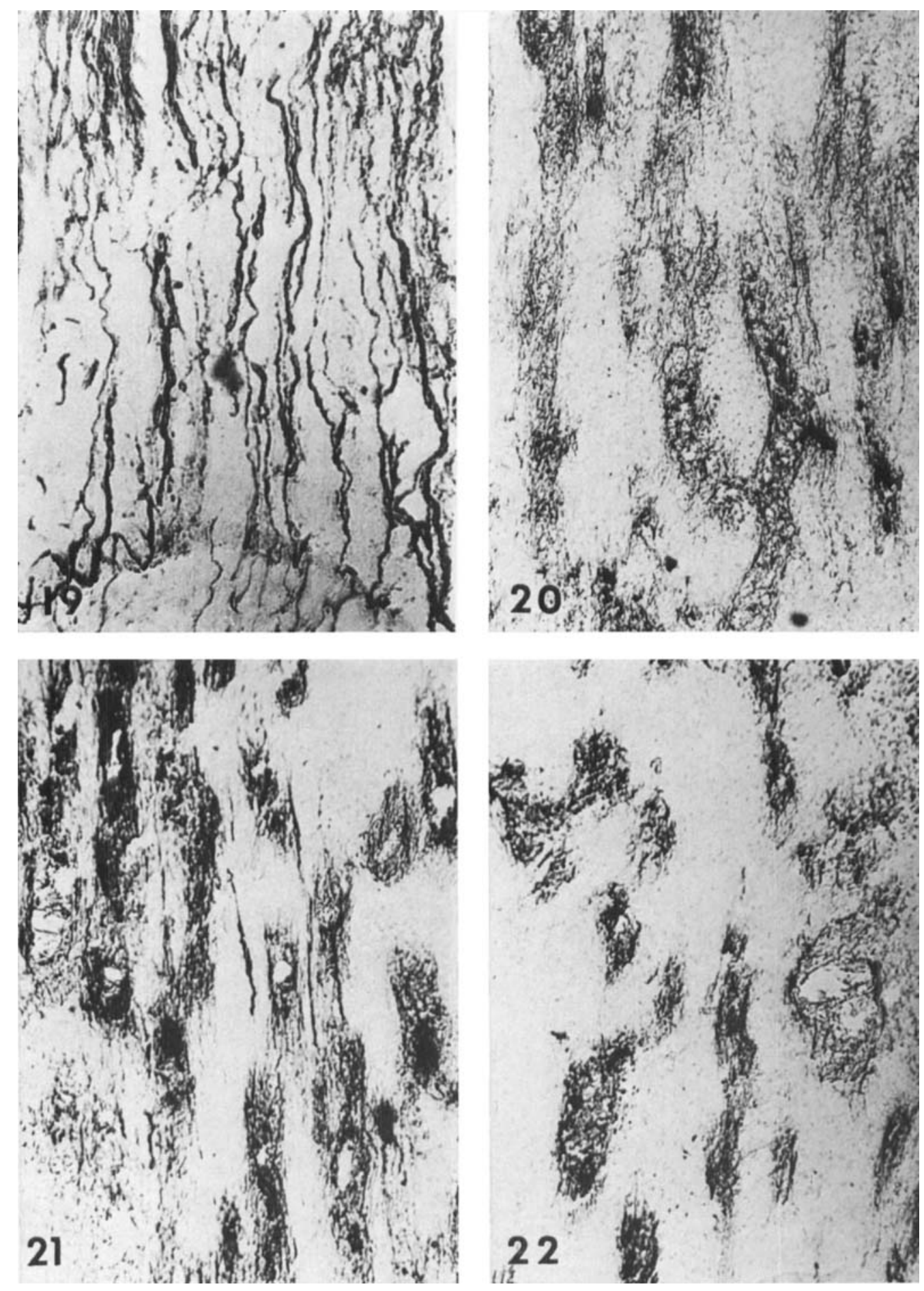

Fig. 19 A section through the middle third of a control rabbit incisal pulp illustrating AChE activity along both nerves and vessel walls. AChE \& D.F.P., $\times 50$.

Fig. 21 A section through the middle third of an S.C.G. resected rabbit incisor pulp (19 days). Pronounced activity appears on the vessels as well as along the nerves of the pulp. Again observe the dense activity on vessel walls. AChE \& D.F.P., $\times 60$.

Fig. 20 A section through the middle third of an I.A.N. resected rabbit incisor pulp (19 days). There is a decrease in AChE activity along nerve trunks, although a strong reaction is seen along the vessels. Observe areas of activity along the vessel walls. AChE \& D.F.P., $\times 60$.

Fig. 22 A longitudinal section through an I.A.N.-S.C.G. resected rabbit incisor pulp. There is a decrease in activity along the nerve trunks. Dense AChE activity is seen along vessel walls. AChE \& D.F.P., $\times 60$. 


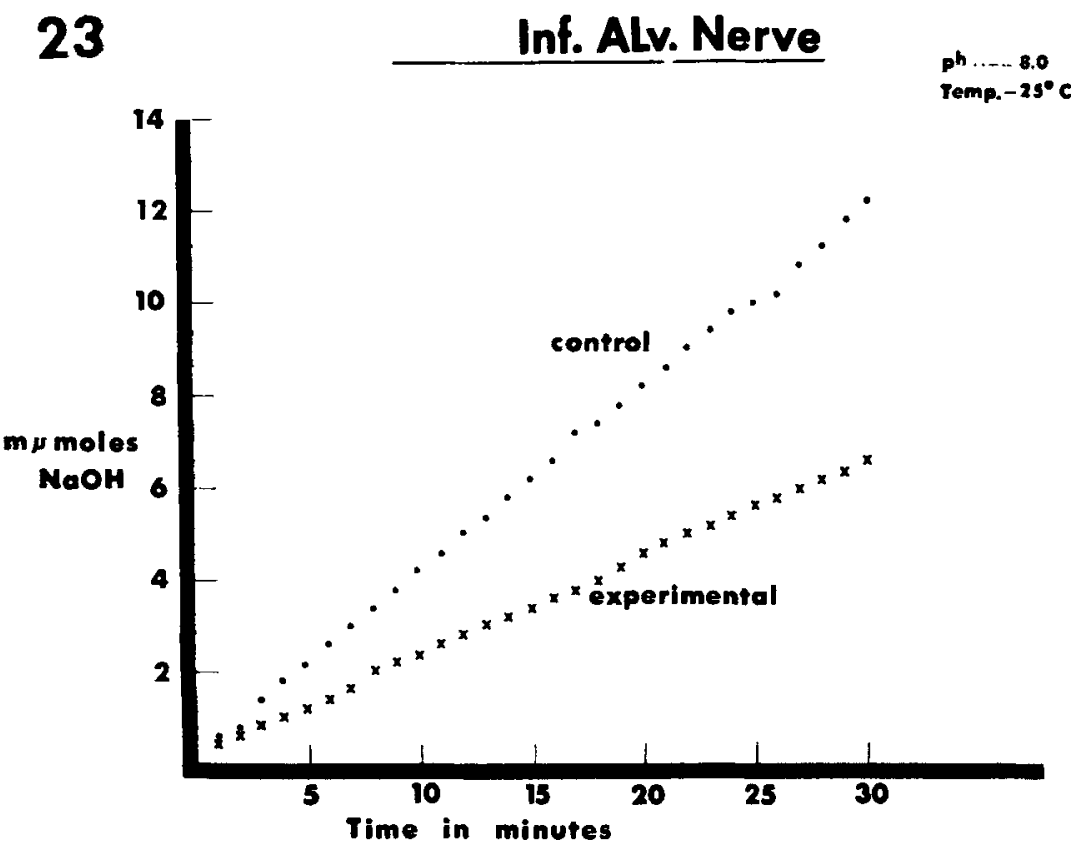

\section{$24 \quad$ Sup. Cerv. Ganglion}

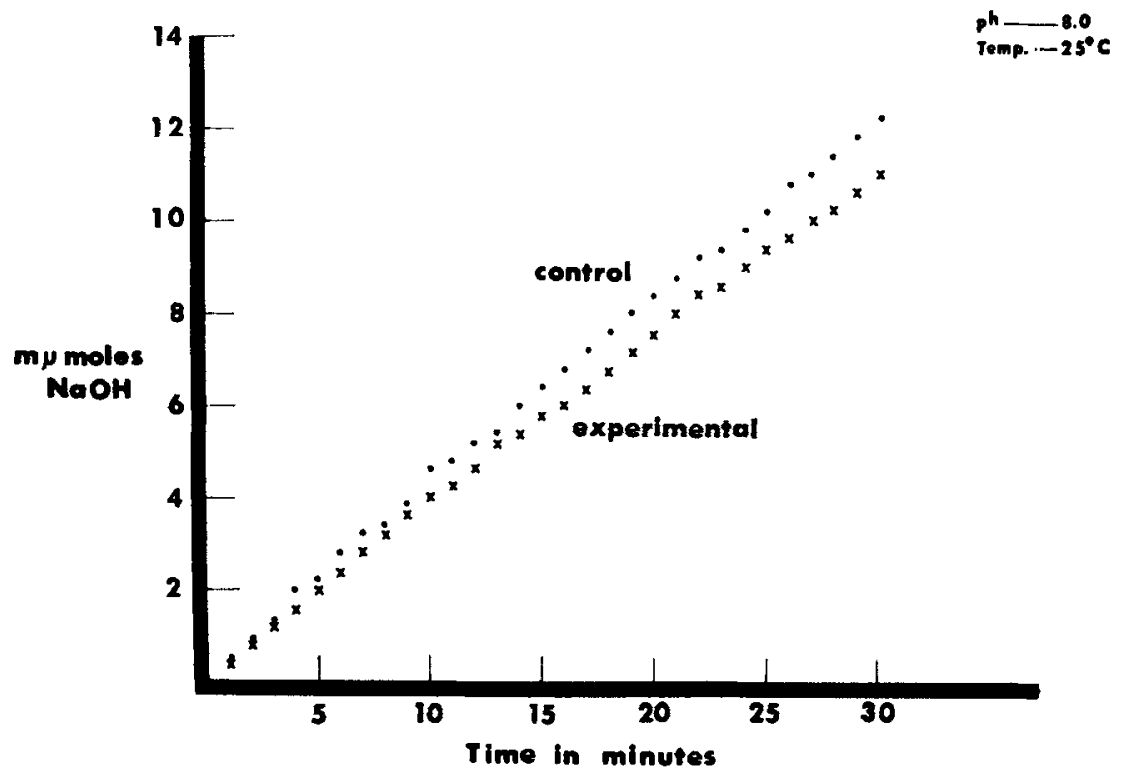

Fig. 23 A random titrametric sample of an I.A.N. resected and a control pulp. A total of $12.70 \mathrm{~m} \mu$ moles was titrated for the control pulp homogenate, while $6.80 \mathrm{~m} \mu$ moles of base were used for the experimental pulp. This represents a significant reduction of acetylcholinesterase in the resected pulp homogenate.

Fig. 24 Removal of the S.C.G. produced the least decrease in cholinesterase concentration. A total of $11.80 \mathrm{~m} \mu$ moles was titrated for the control pulp with $10.60 \mathrm{~m} \mu$ moles titrated for the experimental pulp. The difference of base titrated for the control pulp against the experimental pulp is not significant. 


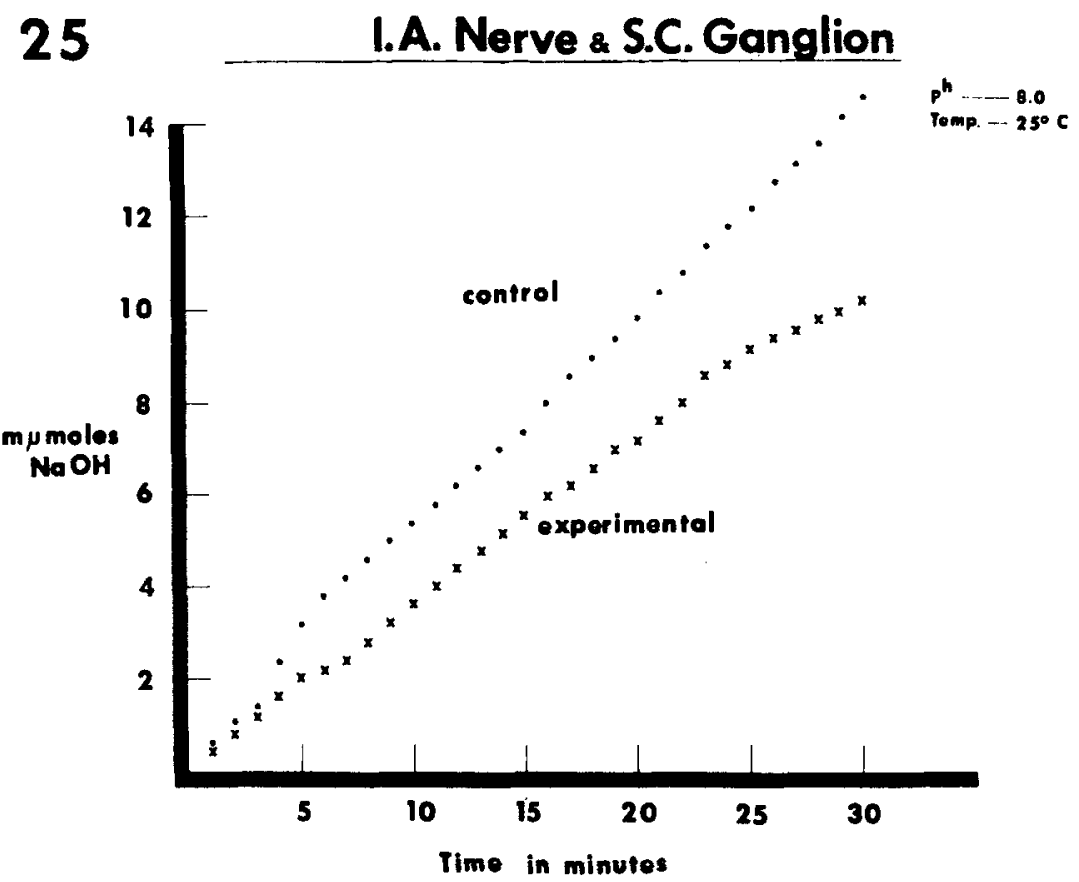

Fig. 25 This graph shows that removal of both I.A.N. and S.C.G. results in a significant decrease in cholinesterase concentration in the incisor pulps. The difference of $4.20 \mathrm{~m} \mu$ moles of base represents the change of acetylcholine hydrolysis as a result of the combined I.A.N.-S.C.G. resection.

\begin{tabular}{|c|c|c|c|c|c|c|c|c|}
\hline 6 & & $\begin{array}{l}\text { ETYLC } \\
1 \mathrm{mpm}\end{array}$ & $\begin{array}{l}\text { HOLINE } \\
\text { oles/min }\end{array}$ & $\begin{array}{l}\text { STERAS } \\
m g \text { issu }\end{array}$ & $A C T I$ & IVITY & & \\
\hline \multicolumn{3}{|c|}{ Inferior Alveolar $\mathrm{N}$. } & \multicolumn{3}{|c|}{ Superior Cerv. Gang. } & \multicolumn{3}{|c|}{ Inf.Alv.N.+ Sup.Cerv.G. } \\
\hline Control & Experm. & Diff. & Control & Experm. & Diff. & Control & Experm. & Diff. \\
\hline 5.7 & 4.6 & 1.1 & 4.1 & 3.7 & 0.4 & 4.9 & 3.4 & 1.5 \\
\hline 6.1 & 5.2 & 0.9 & 4.5 & 4.3 & 0.2 & 4.4 & 3.8 & 0.6 \\
\hline 4.1 & 3.6 & 0.5 & 3.5 & 2.9 & 0.6 & 4.9 & 4.5 & 0.4 \\
\hline 4.1 & 2.2 & 1.9 & 3.0 & 3.4 & 0.4 & 3.4 & 3.1 & 0.3 \\
\hline \multirow{2}{*}{\multicolumn{2}{|c|}{$\begin{array}{l}\text { Mean ........ } \\
\text { Significance }\end{array}$}} & 1.1 & & & 0.4 & & & 0.7 \\
\hline & & $P<.03$ & & & $P<.40$ & & & $P<.25$ \\
\hline
\end{tabular}

Fig. 26 Activity level differences between experimental and control pulp homogenates are recorded. Mean differences for each series are computed and their level of significance noted. 